\title{
Upregulated effects of miR-7 in methicillin-resistant Staphylococcus aureus
}

\author{
HONG ZHANG ${ }^{1}$, HAIQING $\mathrm{LI}^{2}$, YAN LIU ${ }^{3}$, QINGYAN LI ${ }^{1}$, YUFANG BI ${ }^{4}$ and GUIQING FANG ${ }^{5}$ \\ Departments of ${ }^{1}$ Clinical Laboratory and ${ }^{2}$ Nursing, ${ }^{3}$ Health Management Center, and ${ }^{4}$ Operation Room, \\ The Sixth People's Hospital of Jinan, Jinan, Shandong 250200; ${ }^{5}$ Department of Clinical Laboratory, \\ Jinan Stomatological Hospital, Jinan, Shandong 250001, P.R. China
}

Received May 24, 2016; Accepted October 3, 2016

DOI: $10.3892 /$ etm.2016.3805

\begin{abstract}
The aim of the study was to investigate the characteristic function of the upregulated effects of miR-7 in methicillin-resistant Staphylococcus aureus (MRSA). After separating the MRSA in clinic, the expression of miR-7 mRNA was tested by reverse transcription polymerase chain reaction. The overexpression, inhibition of miR-7, and control group were established by plasmid in vitro. Following transfection of the bacterial strain, the effect of $\beta$-lactam antibiotics in minimum inhibitory concentration (MIC) was observed using the microporous dilution method, and antibacterial effects in vitro were observed using the dynamic growth curve method. The expression of miR-7 in sensitive MRSA was upregulated distinctly, with significant difference $(\mathrm{P}<0.05)$. $\mathrm{MIC}$ and the number of bacteria in the miR-7 overexpression group significantly increased while the inhibition group decreased prominently, with significant difference $(\mathrm{P}<0.05)$. The control and null plasmid groups revealed no significant difference. In conclusion, miR-7 upregulated the antimicrobial activity of MRSA, and the intervention of its expression may become a possible antibacterial target.
\end{abstract}

\section{Introduction}

As a super bacteria, methicillin-resistant Staphylococcus aureus (MRSA) shows resistance to a great deal of antibacterial agents, except for a few agents including vancomycin, teicoplanin, and linezolid (1). The domain resistance mechanism of MRSA to $\beta$-lactam antibiotics: i) Producing $\beta$-lactamase, which hydrolyzes $\beta$-lactams ring by means of serine in its active site and then hydrolyzes $\beta$-lactam antibiotics to resist drugs (2);

Correspondence to: Dr Guiqing Fang, Department of Clinical Laboratory, Jinan Stomatological Hospital, 101 Jingliu Road, Jinan, Shandong 250001, P.R. China

E-mail: fang_guiqing1@163.com

Key words: miR-7, methicillin-resistant Staphylococcus aureus, upregulation, microporous dilution method, dynamic growth curve method ii) reducing content of drugs in vivo, including by enhancing permeability of bacterial outer membrane or restraining the active efflux system in bacteria (3); and iii) expressing a great number of special penicillin-binding proteins PBP2a (4). miRNA is a type of untranslated RNA, and $50-75 \%$ of them control transcription and translation with help of binding target mRNA (5). MRSA expresses various types of miRNA abnormally, in particular, the markedly upregulated miR-7 (6).

The aim of the study was to investigate whether miR-7 was associated with the development of MRSA and its possible mechanism, providing a reference for the intervention of MRSA targets.

\section{Materials and methods}

MRSA in clinic. In total, 1,500 samples from the Department of Clinical Laboratory, Jinan Stomatological Hospital (Shandong, China) during the period January 2015 to January 2016 were selected in sequence and were authenticated as well as analyzed by VITEK-2, a fully automatic bacterial identification/drug sensitivity system (bioMérieux, Lyon, France). Seven cases of MRSA were detected $(0.47 \%)$. Criteria of the Clinical and Laboratory Standards Institute (2012) were taken as the reference (7). Agar plate microporous dilution method was used to test the minimum inhibitory concentration (MIC) value from collective MRSA against vancomycin.

Testing the expression of $m i R-7 m R N A$ with reverse transcription polymerase chain reaction (RT-PCR) method. We prepared before the test: PCR Premix Taq reagent and synthesis of the primer (Takara, Tokyo, Japan), electrophoretic buffers and DNA marker (Beijing TransGen Biotech Co., Ltd., Beijing, China), using PCR amplifier (Bio-Rad Laboratories, Inc., Hercules, CA, USA). Whole DNA was extracted by extracting post-resuscitation single bacteria colony from blood agar (plate) and placing it in $500 \mu \mathrm{l}$ tri-distilled water, and then boiling at $100^{\circ} \mathrm{C}$ for $10 \mathrm{~min}$, followed by centrifugation at $4^{\circ} \mathrm{C}$ $10,000 \mathrm{x} \mathrm{g}$ in a refrigerated centrifuge for $10 \mathrm{~min}$. The supernatant after centrifugation was bacterial DNA. Supernatant $(100 \mu \mathrm{l})$ was extracted and delivered to another sterile centrifuge tube, preserved at $-20^{\circ} \mathrm{C}$. Primer sequence: miR-7 forward, 5'-CCGGAATTCAAGAAGCCTTAACCAAGCA-3' and reverse, 5'-CGCGGATCCGAGTAGTAAATCGGACATT 
AGTAGA-3'; internal reference GAPDH forward, 5'-CAAAGT CAAGGCTGAGAAC-3' and reverse, 5'-TGGTGAAGACGC CAGTGG-3'. For the reaction system 2X Taq MasterMix $25 \mu \mathrm{l}$, upstream and downstream primer $(10 \mu \mathrm{M}) 2 \mu \mathrm{l}$, respectively, was used; a DNA template $(4 \mu \mathrm{l})$ was created; and $\mathrm{H}_{2} \mathrm{O}$ was added for a total volume of $50 \mu \mathrm{l}$. The reaction conditions were: Pre-denaturation at $94^{\circ} \mathrm{C}$ for $4 \mathrm{~min}$, denaturation at $94^{\circ} \mathrm{C}$ for $30 \mathrm{sec}$, annealing at $56^{\circ} \mathrm{C}$ for $30 \mathrm{sec}$, and extension at $72^{\circ} \mathrm{C}$ for $1 \mathrm{~min}$. After 35 cycles, extended once more at $72^{\circ} \mathrm{C}$ for $10 \mathrm{~min}$. For sequence analysis, amplicon was extracted for agarose gel electrophoresis, $5 \mu \mathrm{l}$ PCR amplicon for each well, with a voltage $110 \mathrm{~V}$ for $40 \mathrm{~min}$. After electrophoresis, agarose gel was observed in ultraviolet spectrophotometer (Bio-Rad, Hercules, CA, USA). GenBank (https://www.ncbi.nlm.nih. gov/genbank/) was employed for analyzing and comparison of the sequences, and the results are expressed with the $2^{-\Delta \Delta C q}$ method.

Establishment of miR-7 overexpression, inhibition, and control group with plasmid in vitro. TRIzol, liposome transfection reagent (Lipofectamine ${ }^{\mathrm{TM}}$ 2000) was purchased from Invitrogen (Carlsbad, CA, USA). The miRNA RT-PCR kit for RT-PCR was purchased from Applied Biosystems Life Technologies (Foster City, CA, USA), DNA extraction kit and SYBR-Green method RT-PCR kit were purchased from Takara, and 24-well, 96-well plates, Petri dishes were purchased from Corning Costar, Inc. (Corning, NY, USA), and the pCDN3.1 and pCDNA-Sponge-Ready empty carrier was purchased rom R\&D Systems, Inc. (Minneapolis, MN, USA). The synthesis of primer sequence and sequencing was managed by BGI-Tech (Shenzhen, China).

Presequences of miR-7 were amplified from DNA of HepG2 genome, with the same conditions as above. XhoI and HindIII were regarded as insertion site of amplicon. Through genetic recombination, target segment of miR-7 precursor was inserted into pCDNA3.1 carrier and sequenced for detection as well as establishment of overexpression of miR-7. Synthetic length $45 \mathrm{bp}$, oligonucleotide included two repetitive miR-7 reaction sequences (TCGTACCGTGAGTAATAATGCG). Through annealing, oligonucleotide was inserted into pCDNA-Sponge-Ready empty carrier and sequenced for detection as well as establishment of miR-7 interference carrier. According to Lipofection transfection instruction book, 5- $\mu 1$ transfection reagent Lipofectamine ${ }^{\mathrm{TM}} 2000$ and $2-\mu 1$ plasmid were combined and preserved in room temperature for $20 \mathrm{~min}$, then added to cultured supernatant slowly, culturing them after shaking and mixing, and the fluorescence was observed after $24 \mathrm{~h}$.

Observation of the effect of $\beta$-lactam antibiotics in MIC. Vancomycin $10 \mu \mathrm{l}+$ MRSA $190 \mu \mathrm{l}(1,024 \mu \mathrm{g} / \mathrm{ml})$ was in the first well, MRSA $100 \mu \mathrm{l}(512 \mu \mathrm{g} / \mathrm{ml})$ in the second well, MRSA $100 \mu \mathrm{l}(256 \mu \mathrm{g} / \mathrm{ml})$ in the third one, MRSA $100 \mu \mathrm{l}$ $(128 \mu \mathrm{g} / \mathrm{ml})$ in the fourth one, MRSA $100 \mu \mathrm{l}(64 \mu \mathrm{g} / \mathrm{ml})$ in the fifth one, MRSA $100 \mu \mathrm{l}(32 \mu \mathrm{g} / \mathrm{ml})$ in the sixth one, MRSA $100 \mu \mathrm{l}(16 \mu \mathrm{g} / \mathrm{ml})$ in the seventh one, MRSA $100 \mu \mathrm{l}(8 \mu \mathrm{g} / \mathrm{ml})$ in the eighth one, MRSA $100 \mu \mathrm{l}(4 \mu \mathrm{g} / \mathrm{ml})$ in the ninth one, MRSA $100 \mu \mathrm{l}(2 \mu \mathrm{g} / \mathrm{ml})$ in the tenth one, and negative control LB liquid $100 \mu \mathrm{l}$ in the eleventh one. Bacteria solution in the first well and medicine were mixed, $100 \mu \mathrm{l}$ was extracted from

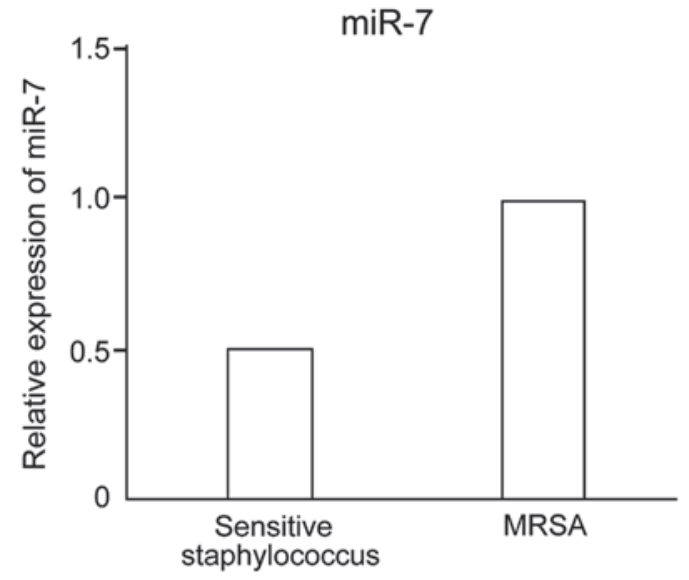

Figure 1. Comparison of the expression of miR-7 mRNA.

the first well and added to the second well. After combination, $100 \mu 1$ was extracted out and added to the third one, double-diluted successively until the tenth one, discarding $100 \mu \mathrm{l}$ in order to keep the volume consistent. Following culture at $37^{\circ} \mathrm{C}$ in an incubator for $48 \mathrm{~h}$ the effect of $\beta$-lactam antibiotics in MIC was observed. The negative well was clear while the positive one was muddy. $\beta$-lactam antibiotics in MIC was the minimum inhibition concentration, which inhibited bacteria from growing at a speed observed by the naked eye.

Antibiotic effect in vitro of bacteria with dynamic growth curve method. After 1/2 MIC concentration of antibiotics was added, and agitated in orbital shaker at $120 \mathrm{x} \mathrm{g}, 37^{\circ} \mathrm{C}$ for $24 \mathrm{~h}$, the OD600 was evaluated of the bacterial liquid in 3, 6, 12 and $24 \mathrm{~h}$, respectively, and the time-bacterial concentration curve was drawn.

Statistical analysis. Data were analyzed by SPSS 20.0 software (SPSS Inc., Chicago, IL, USA). Quantitative data were assessed by mean \pm standard deviation. Differences between the two groups were assessed by Student's t-test, differences among the multiple groups were assessed by single-factor analysis of variance (ANOVA), and the two groups were compared by least significant difference method. Different time data in the groups were compared by ANOVA of repetitive data, $\mathrm{P}<0.05$ was considered to indicate a statistically significant difference.

\section{Results}

Expression of miR-7 mRNA. The expression of miR-7 mRNA in sensitive MRSA was upregulated distinctly, with significant difference $(\mathrm{P}<0.05)$ (Fig. 1).

Comparison of the MIC of vancomycin in MRSA. MIC in miR-7 overexpression group increased drastically while in inhibition group it decreased prominently, with significant difference $(\mathrm{P}<0.05)$. Control group and null plasmid group show no significant difference (Fig. 2).

Time-bacterial concentration curve. OD600 value of different time-points in miR-7 overexpression group, numbers of bacteria, increased significantly while it decreased in inhibition 


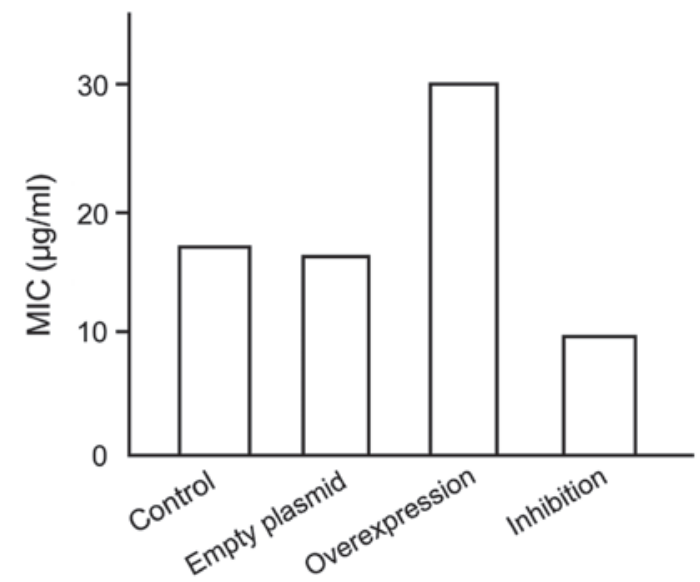

Figure 2. Comparison of MIC of vancomycin in MRSA. MIC, minimum inhibitory concentration; MRSA, methicillin-resistant Staphylococcus aureus.

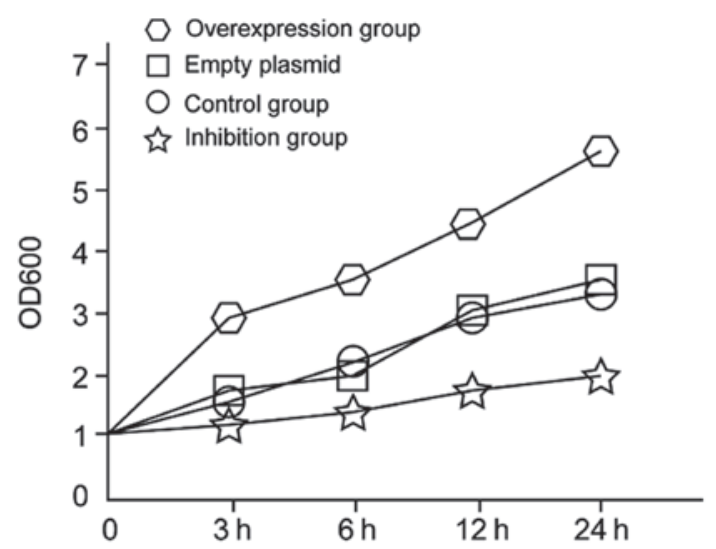

Figure 3. Time-bacterial concentration curve.

group, with significant difference $(\mathrm{P}<0.05)$. Control group and null plasmid group showed no significant difference (Fig. 3).

\section{Discussion}

Previously, studies of miRNAs were concentrated mainly on eucaryon, and various functional miRNAs were found, which would be complementary with target gene and then regulated the expression of a particular gene (8). With the development of research on prokaryotes, there are similar non-coded miRNAs found in bacteria, carrying out a variety of functions which associate with development, reproduction, antibacterial activity, resistance and variation of bacteria (9).

A great deal of miRNAs in bacteria is closely associated with the development and metabolism and toxicity regulation procedures (10). Research on miRNAs of prokaryote was concentrated mainly on Escherichia coli, and hundreds of miRNAs were found (11). Recent findings suggested that there were new miRNAs in gram-positive Staphylococcus aureus. Of these, partly located in pathogenicity islands of Staphylococcus aureus genome or only existing in pathogenicity bacteria, indicated that miRNAs probably participated in regulating the expression of pathogenic bacteria toxicity (12). RNAIII of Staphylococcus aureus (a type of miRNA) was verified as a toxicity-associated gene, participating the regulation of Staphylococcus aureus pathogenicity (13). Hfq protein was first found in Escherichia coli, owing to chaperone activity of RNA, whose main biological function was to affect RNA stability through hexamer and combined with RNA or to regulate the expression of target genes by assisting a combination of miRNAs and mRNA. This is vital for miRNA function through comparison (14). During research on gene expression regulation, some transcriptional-level control miR-7 molecule needs the assistance of $\mathrm{Hfq}$ protein, indicating that the miRNAs may be a family whose characteristic was the combination with Hfq protein effectively, and to be affected with target mRNA molecules through base pairing and then regulated the expression of target mRNA (15). At present, in Escherichia coli, more than $30 \%$ non-coding miRNAs are found to be able to combine with Hfq protein (16).

In conclusion, the expression of miR-7 in sensitive MRSA was clearly upregulated. MIC and number of bacteria in miR-7 overexpression group increased greatly while in inhibition group they decreased prominently, with significant difference. miR-7 upregulated the antimicrobial activity of MRSA, and the intervention of its expression may become a possible antibacterial target. Whether miR-7 upregulated the antimicrobial activity of MRSA associated with the Hfq protein assistant regulated effect, development of MBL as well as expression mechanism of porin OprC, and relevant cell signal pathway is still needed and should be explored.

\section{References}

1. Hale CM, Seabury RW, Steele JM, Darko W and Miller CD: Are vancomycin trough concentrations of 15 to $20 \mathrm{mg} / \mathrm{L}$ associated with increased attainment of an AUC/MIC $\geq 400$ in patients with presumed MRSA infection? J Pharm Pract 12: 12-13, 2016.

2. Aktaş Z, Satana D, Kayacan C, Can B, Gönüllü N and Küçükbasmacı O: Antibiotic susceptibility rates and beta-lactam resistance mechanisms of Pseudomonas aeruginosa strains. Mikrobiyol Bul 46: 386-397, 2012 (In Turkish).

3. Li H, Luo YF, Williams BJ, Blackwell TS and Xie CM: Structure and function of OprD protein in Pseudomonas aeruginosa: from antibiotic resistance to novel therapies. Int J Med Microbiol 302: 63-68, 2012.

4. Harrison EM, Ba X, Blane B, Ellington MJ, Loeffler A, Hill RL, Holmes MA and Peacock SJ: PBP2a substitutions linked to ceftaroline resistance in MRSA isolates from the UK. J Antimicrob Chemother 71: 268-269, 2016.

5. Ostojić M and Hukić M: Genotypic and phenotypic characteristics of methicillin-resistant Staphylococcus aureus (MRSA) strains, isolated on three different geography locations. Bosn J Basic Med Sci 15: 48-56, 2015.

6. Yang R, Zheng T, Cai X, Yu Y, Yu C, Guo L, Huang S, Zhu W, Zhu R, Yan Q, et al: Genome-wide analyses of amphioxus microRNAs reveal an immune regulation via miR-92d targeting C3. J Immunol 190: 1491-1500, 2013.

7. Magiorakos AP, Srinivasan A, Carey RB, Carmeli Y, Falagas ME, Giske CG, Harbarth S, Hindler JF, Kahlmeter G, Olsson-Liljequist $\mathrm{B}$, et al: Multidrug-resistant, extensively drug-resistant and pandrug-resistant bacteria: an international expert proposal for interim standard definitions for acquired resistance. Clin Microbiol Infect 18: 268-281, 2012.

8. Datta J, Islam M, Dutta S, Roy S, Pan Q and Teknos TN: Suberoylanilide hydroxamic acid inhibits growth of head and neck cancer cell lines by reactivation of tumor suppressor microRNAs. Oral Oncol 56: 32-39, 2016.

9. Li MM, Addepalli B, Tu MJ, Chen QX, Wang WP, Limbach PA, LaSalle JM, Zeng S, Huang $M$ and Yu AM: Chimeric microRNA-1291 biosynthesized efficiently in Escherichia coli is effective to reduce target gene expression in human carcinoma cells and improve chemosensitivity. Drug Metab Dispos 43: 1129-1136, 2015 
10. Li MM, Wang WP, Wu WJ, Huang M and Yu AM: Rapid production of novel pre-microRNA agent hsa-mir-27b in Escherichia coli using recombinant RNA technology for functional studies in mammalian cells. Drug Metab Dispos 42: $1791-1795,2014$

11. Jin W, Ibeagha-Awemu EM, Liang G, Beaudoin F, Zhao X and Guan L: Transcriptome microRNA profiling of bovine mammary epithelial cells challenged with Escherichia coli or Staphylococcus aureus bacteria reveals pathogen directed microRNA expression profiles. BMC Genomics 15: 181, 2014.

12. Sun J, Aswath K, Schroeder SG, Lippolis JD, Reinhardt TA and Sonstegard TS: MicroRNA expression profiles of bovine milk exosomes in response to Staphylococcus aureus infection. BMC Genomics 16: 806, 2015.

13. Zhou Y, Zhao R, Ma B, Gao H, Xue X, Qu D, Li M, Meng J, Luo $X$ and Hou Z: Oligomerization of RNAIII-inhibiting peptide inhibits adherence and biofilm formation of methicillin-resistant Staphylococcus aureus in vitro and in vivo. Microb Drug Resist 22: 193-201, 2016.
14. Gupta RK, Luong TT and Lee CY: RNAIII of the Staphylococcus aureus agr system activates global regulator MgrA by stabilizing mRNA. Proc Natl Acad Sci USA 112: 14036-14041, 2015.

15. Ma B, Zhou Y, Li M, Yu Q, Xue X, Li Z, Da F, Hou Z and Luo X: RIP-V improves murine survival in a sepsis model by down-regulating RNAIII expression and $\alpha$-hemolysin release of methicillin-resistant Staphylococcus aureus. Pharmazie 70: 81-87, 2015

16. Zhang X, Zhu Q, Tian T, Zhao C, Zang J, Xue T and Sun B: Identification of RNAIII-binding proteins in Staphylococcus aureus using tethered RNAs and streptavidin aptamers based pull-down assay. BMC Microbiol 15: 102, 2015. 